\title{
Prediction of Glucose, Fructose and Sucrose content in Cassava (Manihot esculenta Crantz) genotypes from Amazon using PLS models
}

\author{
Arthur Abinader Vasconcelos ${ }^{1 *}$, Roberto Lisboa Cunha ${ }^{2}$, Elisa Ferreira Moura Cunha ${ }^{2}$, \\ Willison Eduardo Oliveira Campos ${ }^{3}$, Paulo Sérgio Taube ${ }^{1}$, Heronides Adonias Dantas Filho ${ }^{3}$ \\ ${ }^{1}$ Universidade Federal do Oeste do Pará, Rua Vera Paz s/n, CEP: 68035-110, Santarém, PA, Brazil \\ ${ }^{2}$ Embrapa Amazônia Oriental, Trav. Dr. Enéas Pinheiro, s/n, CEP: 66095-903, Belém, PA, Brazil \\ ${ }^{3}$ Universidade Federal do Pará, Rua Augusto Corrêa, 01, CEP: 66075-110, Belém, PA, Brazil
}

\section{Graphical Abstract}

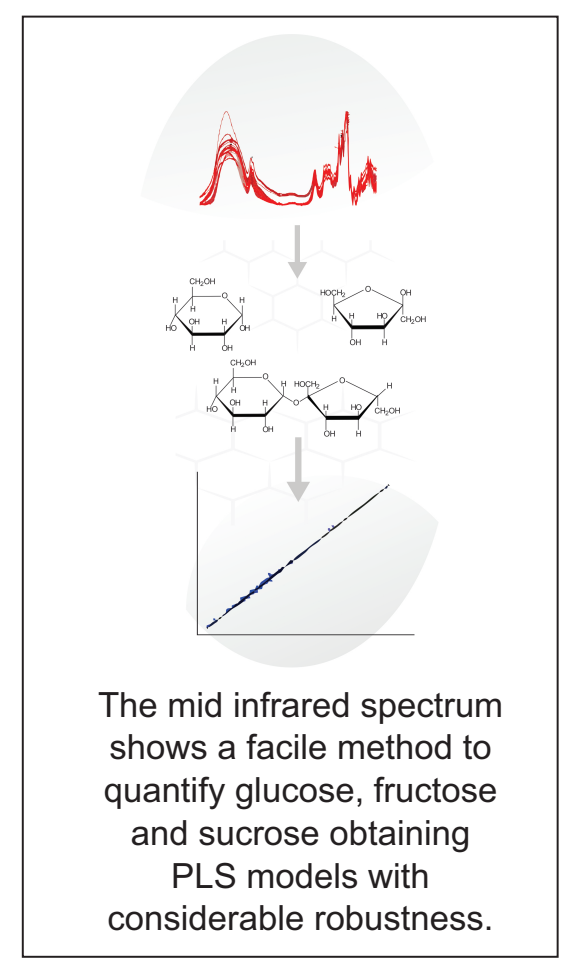

The chemical characterization by classical methods requires a long time of analysis and the use of expensive and environmentally aggressive reagents. The use of the partial least squares (PLS) tool applied to FT-MIR data represents a reduction of these considered variables. The relative contributions of glucose, fructose, and sucrose obtained for the 26 cassava samples varied between $0.111-0.383 \mathrm{~g} / 100 \mathrm{~g} ; 0.0317-0.256 \mathrm{~g} / 100 \mathrm{~g}$ and $0.286-0.775 \mathrm{~g} / 100 \mathrm{~g}$, respectively. For five latent variables the mean of predicted glucose content in external samples was $0.220 \mathrm{~g} / 100 \mathrm{~g}$ and had the RMSEP value of $0.00590 \mathrm{~g} / 100 \mathrm{~g}$; The best number of LVs for the prediction of the fructose content for new samples were five, where the mean of the predicted value was $0.0994 \mathrm{~g} / 100 \mathrm{~g}$ against the mean fructose reference value $0.0879 \mathrm{~g} / 100 \mathrm{~g}$, with a $0.0115 \mathrm{~g} / 100 \mathrm{~g}$ RMSEP; The mean sucrose content in the external samples was $0.451 \mathrm{~g} / 100 \mathrm{~g}$, compared with the reference value $0.515 \mathrm{~g} / 100 \mathrm{~g}$, with a RMSEP $0.138 \mathrm{~g} / 100 \mathrm{~g}$. The use of the PLS1 algorithm generated two good models with the second derivative in spectral data and one with the raw data in spectral data using four samples external to the prediction step.

Keywords: Partial least squares, PLS, cassava, spectroscopy, Amazon region.

\section{INTRODUCTION}

Cassava root has great importance both in economic and nutritional aspects, since the genus has approximately 98 species, with Manihot esculenta being the most cultivated in tropical regions [1]. The consumption of cassava in Africa is great, and in Mozambique its marketing can reach more than 240 million dollars. In other regions of the world, it is consumed by approximately 700 million people $[2,3]$.

The content of glycines in the cassava root is closely related to the starch content present because this plant structure is essentially starchy with low protein, lipid and ash contents.

Other carbohydrates of different molecular weights may be present, from sugars to glycosides and cellulosic material. Therefore, the root is a fundamental raw material for obtaining sugars by hydrolysis process, which has been used in recent years by the sugar industry, mainly in enzymatic processes to obtain glucose and fructose syrups, used in the pharmaceutical and food industry [4]. 
Sucrose levels in vitro culture influence diverse metabolic processes in cassava such as tissue differentiation and growth. The trend of studies involving sugars content in amylaceous sources is reflected in the ethanol obtained from the hydrolysis of cassava starch from syrups.

The improvement of instrumental methodologies with few uses of the high amount of chemicals is a good environmental alternative. Among these techniques, the Fourier transform medium infrared spectroscopy (FT-MIR) stands out because it is a simple, fast and inexpensive technique that has been used with chemometric tools such as Partial Least Squares Regression (PLS) to quantify some classic parameters of local models.

The medium infrared (MIR) region shows promise since foods are mainly composed of water, carbohydrates, proteins, lipids and other minor components such as vitamins and minerals, all of these compounds have the ability to absorb radiation.

Thus, the quantification of the compounds is possible from the evaluation of the intensity and region characteristic of the absorption bands of the main functional groups present. If signals are intercepted, it is often possible to extract spectral data more efficiently using multivariate mathematical methods [5].

Many authors report the importance of using chemometric tools coupled to infrared spectroscopy to evaluate some chemical properties of food, where PLS modeling has been the most widely used chemometric tool in recent years [6-15].

The multivariate calibration models generated for a universe of samples allow the creation of a local model in which new samples with similar spectral characteristics can be inserted and the parameter is quickly determined. Thus, it is increasingly necessary to explore this procedure, as shown by some recently published studies $[16,17]$.

The present work aims to use data from a reference method for quantification of glucose, fructose, and sucrose to create PLS models by FT-MIR spectral data.

\section{MATERIALS AND METHODS}

\section{Sample preparation}

A total of 30 cassava genotypes were planted in the municipality of Igarapé Açu, Pará state, Brazil $\left(01^{\circ} 07^{\prime} 33^{\prime \prime S}\right.$ and $\left.47^{\circ} 37^{\prime} 27^{\prime \prime} \mathrm{W}\right)$ in an active germplasm bank of an experimental area of the Brazilian Company of Agricultural Research (Embrapa). The 26 samples were used for the construction of calibration models and 4 samples were used as external samples for prediction.

The general characteristics of the planting site are medium-textured yellow latosol, "Am" type in the Köppen classification, with high annual precipitation (over 2,350 mm). The average annual temperature is around $25^{\circ} \mathrm{C}$ and relative humidity around $85 \%$.

After one year of planting, the samples were harvested, taken with running water, packed in plastic bags and stored under refrigeration between -18 and $-4{ }^{\circ} \mathrm{C}$. They were peeled and cut into plastic planks, forming disks with approximately $2 \mathrm{~cm}$, and separated in triplicates. After cutting, samples were ground and transferred to $50 \mathrm{~mL}$ Falcon tubes previously decontaminated with $10 \%(\mathrm{v} / \mathrm{v}) \mathrm{HCl}$ aqueous solution and taken to the freezer where they remained at $-18^{\circ} \mathrm{C}$ for $24 \mathrm{~h}$.

The frozen samples were then lyophilized for $96 \mathrm{~h}$ to ensure removal of as much water as possible. The lyophilized samples were then crushed in an agate mortar and transferred to $80 \mathrm{~mL}$ plastic vials previously decontaminated with $10 \%(\mathrm{v} / \mathrm{v}) \mathrm{HCl}$ aqueous solution and stored in dissent at room temperature until further analysis.

\section{Determination of glucose, fructose, and sucrose by Elisa method}

A mass of $0.2 \mathrm{~g}$ of fresh root was macerated and the sugars were extracted with $80 \%(\mathrm{v} / \mathrm{v})$ of ethanol. An aliquot of $5 \mu \mathrm{L}$ of ethanolic extract and $5 \mu \mathrm{L}$ of hexokinase, phosphoglucoisomerase and $\beta$-fructosidase enzymes were used to determine the different sugars. Absorbance reading was performed on an ELISA plate reader (Thermo Scientific Multiskan® FC Microplate Photometer) using a wavelength of $340 \mathrm{~nm}$ [18]. 


\section{FT-MIR analysis}

Analysis by medium infrared spectroscopy was performed by the ATR method. Samples were used in triplicates using $1 \mathrm{mg}$ of each lyophilized sample.

The background of each sample was obtained by the environment spectral record. The samples were analyzed on infrared spectrometer as Fourier transform (Thermo Fisher Scientific Inc., model Nicolet) with a spectral range between 4000 and $500 \mathrm{~cm}^{-1}$. The instrumental analysis parameters were: spectral resolution $4 \mathrm{~cm}^{-1}, 32$ scans per spectrum, correcting the bands of water and carbon dioxide.

\section{Multivariate analysis}

The PLS models were created from FT-MIR data, which were processed by the software Unscrambler 9.1@ (CAMO Software AS). The spectral data were converted to the matrix form using mean absorbance values obtained in 600-1450, 2900-3000 and $3300 \mathrm{~cm}^{-1}$.

The validation method adopted was cross-validation of the complete segment of a sample. The elimination of anomalous samples was done according to the leverage values and the residual variance of matrix $\mathrm{Y}$, in addition to the automatic detection by the program.

The data of the matrices $X$ and $Y$ were not weighted, initially being constructed models for 10 PCs (principal components), observing the precision of each model with the elimination of abnormal samples and $\mathrm{PC}$ reduction.

The data from both matrices were centered on the mean, the models were constructed by performing pre-processing of the spectral data to verify the optimization of the spectral responses in the determination of each parameter, obtaining a total of 9 models constructed for each parameter. The spectral preprocesses used to construct the models were: raw data, normalized data, normalized first derivative data, normalized second derivative data, first derivative MSC, second derivative MSC, MSC with normalization, first derivative and second derivative.

For the prediction step the spectra of 4 external cassava samples, in the same wavenumbers of calibration samples were used, using the average content of each parameter as a reference value.

\section{RESULTS AND DISCUSSION}

\section{Sugars contents by ELISA analysis}

The analytical parameters of validation to Elisa analysis are shown in Table I.

Table I. Validation parameters for sugars quantification

\begin{tabular}{lccc}
\hline Parameter & Glucose & Fructose & Sucrose \\
\hline $\operatorname{LOD}(\mathrm{g} / 100 \mathrm{~g})$ & 0.0105 & 0.0120 & 0.0160 \\
$\operatorname{LOQ}(\mathrm{g} / 100 \mathrm{~g})$ & 0.0315 & 0.0300 & 0.0480 \\
$\operatorname{Recovery}(\%)$ & 120 & 115 & 105 \\
\hline
\end{tabular}




\section{Article}

The glucose, fructose and sucrose contents obtained by Elisa analysis are shown in Table II.

Table II. Contents of sugars in cassava samples

\begin{tabular}{lccc}
\hline Samples ID & Glucose $(\mathbf{g} / \mathbf{1 0 0 g})$ & Fructose $(\mathbf{g} / \mathbf{1 0 0 g})$ & Sucrose $(\mathbf{g} / \mathbf{1 0 0 g})$ \\
\hline IJ & $0.258 \pm 0,0712$ & $0.103 \pm 0.00230$ & $0.775 \pm 0.124$ \\
CH & $0.201 \pm 0.0320$ & $0.0507 \pm 000193$ & $0.382 \pm 0.00291$ \\
OV & $0.185 \pm 0.0173$ & $0.0391 \pm 0.00278$ & $0.464 \pm 0.0545$ \\
MA & $0.173 \pm 0.0477$ & $0.0521 \pm 0.0364$ & $0.616 \pm 0.0309$ \\
CP1 & $0.288 \pm 0.114$ & $0.0375 \pm 0.0165$ & $0.502 \pm 0.001$ \\
DI & $0.282 \pm 0.0808$ & $0.182 \pm 0.0514$ & $0.428 \pm 0.0557$ \\
CP2 & $0.217 \pm 0.0721$ & $0.0881 \pm 0.0093$ & $0.489 \pm 0.0182$ \\
CP3 & $0.297 \pm 0.0703$ & $0.0751 \pm 0.000969$ & $0.439 \pm 0.0616$ \\
MN & $0.236 \pm 0.0302$ & $0.0704 \pm 0.00630$ & $0.508 \pm 0.0889$ \\
TM & $0.216 \pm 0.0875$ & $0.0356 \pm 0.00375$ & $0.479 \pm 0.0406$ \\
OP & $0.347 \pm 0.156$ & $0.196 \pm 0.0717$ & $0.337 \pm 0.00551$ \\
JA & $0.227 \pm 0.0596$ & $0.0826 \pm 0.0931$ & $0.394 \pm 0.0754$ \\
JB & $0.383 \pm 0.125$ & $0.104 \pm 0.00327$ & $0.471 \pm 0.0457$ \\
T1 & $0.244 \pm 0.0766$ & $0.0697 \pm 0.00751$ & $0.736 \pm 0.0137$ \\
T2 & $0.324 \pm 0.0748$ & $0.141 \pm 0.0317$ & $0.616 \pm 0.0125$ \\
AM & $0.343 \pm 0.0640$ & $0.256 \pm 0.0435$ & $0.529 \pm 0.0234$ \\
AT & $0.189 \pm 0.0436$ & $0.0697 \pm 0.00497$ & $0.759 \pm 0.0267$ \\
AMR & $0.164 \pm 0.0708$ & $0.0591 \pm 0.00339$ & $0.624 \pm 0.0772$ \\
P24 & $0.190 \pm 0.0496$ & $0.0612 \pm 0.00569$ & $0.637 \pm 0.0469$ \\
BMG & $0.124 \pm 0.00497$ & $0.0911 \pm 0.00169$ & $0.387 \pm 0.00254$ \\
SB & $0.115 \pm 0.0342$ & $0.0567 \pm 0.0168$ & $0.303 \pm 0.0209$ \\
SAP & $0.166 \pm 0.0172$ & $0.122 \pm 0.00775$ & $0.452 \pm 0.0963$ \\
CE & $0.0966 \pm 0.0304$ & $0.0317 \pm 0.00575$ & $0.286 \pm 0.0136$ \\
PV & $0.194 \pm 0.0234$ & $0.0779 \pm 0.00303$ & $0.767 \pm 0.00887$ \\
PE & $0.111 \pm 0.0132$ & $0.0662 \pm 0.0126$ & $0.610 \pm 0.0704$ \\
CPATU & $0.172 \pm 0.0127$ & $0.0411 \pm 0.00327$ & $0.473 \pm 0.0203$ \\
\hline & & & \\
A & &
\end{tabular}

\section{FT-MIR and multivariate calibration results}

A total of 26 spectra were generated for each sample in triplicate $(\mathrm{N}=3)$, after this, the mean of spectra is calculated. The spectrum of the 26 samples is shown in Figure 1. 




Figure 1. Mean FT-MIR spectrum of each sample.

The spectral data shown in Figure 1 allows extracting the main region responsible to inform carbohydrate fingerprints to generate models based on nine pre-treatments. The regions that were extracted varied from 1000 to $1400 \mathrm{~cm}^{-1}$, which includes the fingerprint region $\left(900-1200 \mathrm{~cm}^{-1}\right)$, useful in the analysis of carbohydrates [19]. In addition to the region from 3229.61 to $3301.53 \mathrm{~cm}^{-1}$, which contains more relevant information about the $\mathrm{OH}$ group from the hydrocarbon chains.

The correlation coefficient in the calibration step reached the ideal value $(\approx 1.0)$ with a lower number of PCs. Table III shows the diagnostic parameters of the calibration and validation steps for the glucose prediction model.

Table III. Calibration and validation parameters for each glucose model

\begin{tabular}{|c|c|c|c|c|}
\hline Model & RMSEC & Y- explained variance/\% & $r^{2}$ & RMSECV \\
\hline Crude data ${ }^{a}$ & $0.0513\left(3^{b}\right)$ & $56.00(3)$ & $0.7483(3)$ & $0.0608(2)$ \\
\hline MSC/1st Derivative ${ }^{a}$ & $0.0359(6)$ & $69.57(6)$ & $0.8341(6)$ & $0.0509(2)$ \\
\hline $\mathrm{MSC} / 2^{\text {nd }}$ Derivative & $0.0156(6)$ & $95.89(6)$ & $0.9792(6)$ & $0.0888(2)$ \\
\hline MSC/Normalization & $0.0065(6)$ & $98.98(6)$ & $0.9949(6)$ & $0.0830(2)$ \\
\hline Normalization/1 $1^{\text {st }}$ Derivative & $0.0167(6)$ & $94.74(6)$ & $0.9733(6)$ & $0.0822(3)$ \\
\hline Normalization/2 ${ }^{\text {nd }}$ Derivative & $0.0226(6)$ & $90.90(6)$ & $0.9534(6)$ & $0.0895(1)$ \\
\hline Normalization & $0.0086(6)$ & $98.02(6)$ & $0.9900(6)$ & $0.0459(8)$ \\
\hline $1^{\text {st }}$ Derivative & $0.0229(6)$ & $89.83(6)$ & $0.9478(6)$ & $0.0933(4)$ \\
\hline $2^{\text {nd }}$ Derivative & $0.0078(6)$ & $98.86(6)$ & $0.9943(6)$ & $0.0926(3)$ \\
\hline
\end{tabular}

${ }^{a}$ Models submitted to Marten's uncertainty test; ${ }^{b}$ Number of PCs.

According to Table II, the calibration models with the best diagnostic parameters were those with MSC/ Normalization and second derivative, so the next step was to verify the predictive power of the glucose content of each one for the external samples.

Figure 2 shows the prediction of the model with an only second derivative of the spectral data, proving that this better predicts the glucose content in new samples compared to the average of glucose level.

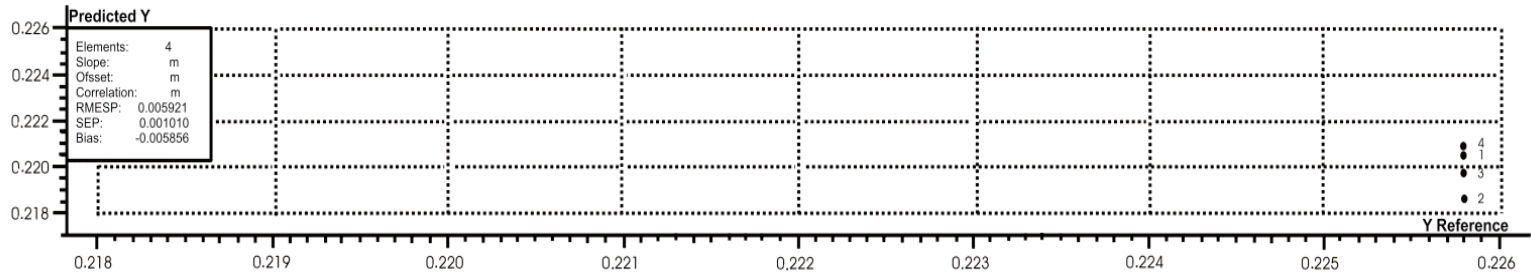

Figure 2. Prediction of glucose content. 
For four latent variables, the predicted mean glucose content had the RMSEP value of $0.0059 \mathrm{~g} / 100 \mathrm{~g}$ (second derivative) versus $1.9266 \mathrm{~g} / 100 \mathrm{~g}$ (MSC/normalization) for the same number of latent variables. The mean value predicted for glucose was $0.220 \mathrm{~g} / 100 \mathrm{~g}$ versus the mean value of $0.226 \mathrm{~g} / 100 \mathrm{~g}$ determined by Elisa method.

For six latent variables, the second derivative model had RMSEP and SEP equal to $0.0063 \mathrm{~g} / 100 \mathrm{~g}$ and $0.0011 \mathrm{~g} / 100 \mathrm{~g}$ respectively, while the other model had RMSEP and SEP equal to $2.1686 \mathrm{~g} / 100 \mathrm{~g}$ and $0.2079 \mathrm{~g} / 100 \mathrm{~g}$ respectively. The high SEP value indicated that although the calibration set was adequate, the model has probably high residues as the result of pre-processing of the spectral data.

Authors evaluating cassava biomass parameters by PLS-DA regression found higher prediction errors for 4 latent variables in the prediction of ash, potassium and chlorine contents [20]. The errors had a factor of 10 relative to the errors found, showing the robustness of the obtained model. Other authors report the use of PLS to Lotus seed infrared data, generating models with a maximum of 4 latent variables for parameter prediction, however, the authors performed few pre-treatments [21].

Some authors obtained differences in glucose prediction parameters by the differential use of accessories in the spectrometer. Reporting SEP value between 0.46 and $0.38 \mathrm{mg} / \mathrm{g}$ for the use of ATR mode and dial-path respectively [22]. Thus, not only logical data processing is fundamental in a PLS analysis, but the proper use of accessories in the equipment as well.

Table IV shows the performance parameters of the models created for the prediction of fructose content.

Table IV. Calibration and validation parameters for each fructose model

\begin{tabular}{|c|c|c|c|c|}
\hline Model & RMSEC & Y-explained variance / \% & $r^{2}$ & RMSECV \\
\hline Crude data & $0.0046\left(8^{\mathrm{a}}\right)$ & $99.44(8)$ & $0.9972(1)$ & $0.0678(1)$ \\
\hline $\mathrm{MSC} / 1^{\text {st }}$ Derivative & $0.0029(8)$ & $99.55(8)$ & $0.9977(1)$ & $0.0541(1)$ \\
\hline $\mathrm{MSC} / 2^{\text {nd }}$ Derivative & $0.00064(7)$ & $99.98(7)$ & $0.9999(7)$ & $0.0504(1)$ \\
\hline MSC/Normalization & $0.0014(7)$ & $99.92(7)$ & $0.9996(7)$ & $0.0702(4)$ \\
\hline Normalization $/ 1^{\text {st }}$ Derivative & $0.0022(7)$ & $99.76(7)$ & $0.9988(7)$ & $0.061(2)$ \\
\hline Normalization $/ 2^{\text {nd }}$ Derivative & $0.0061(8)$ & $98.38(8)$ & $0.9918(8)$ & $0.0519(2)$ \\
\hline Normalization & $0.0011(8)$ & $99.93(8)$ & $0.9996(8)$ & $0.0523(1)$ \\
\hline $1^{\text {st }}$ Derivative & $0.0096(8)$ & $95.75(8)$ & $0.9785(8)$ & $0.0517(1)$ \\
\hline $2^{\text {nd }}$ Derivative & $0.0050(8)$ & $98.84(8)$ & $0.9941(8)$ & $0.0488(2)$ \\
\hline
\end{tabular}

${ }^{a}$ number of PCs

The best models obtained with better parameters of calibration and validation were second derivative, MSC/Normalization, Normalization/ $1^{\text {st }}$ Derivative and Normalization $/ 2^{\text {nd }}$ Derivative. The models that had the best RMSECV value with 1 principal component were inadequate, due to the increase of error.

Among the best models, the one with the second derivative was the most robust, because the validation error reached the lowest value with only 2 LVs in comparison to the others. To prove that this model was able to predict better than the other three that are shown in Table $\mathrm{V}$.

Table V. RMSEP values to predict fructose contents in external samples

\begin{tabular}{|c|c|c|c|c|}
\hline Model & $1 \mathrm{LV}$ & $2 \mathrm{LV}$ & $3 \mathrm{LV}$ & $4 \mathrm{LV}$ \\
\hline MSC/Normalization & 0.1551 & 0.0541 & 2.8145 & 2.7892 \\
\hline Normalization $/ 1^{\text {st }}$ Derivative & 0.0993 & 0.2626 & 0.2355 & 0.1806 \\
\hline Normalization $/ 2^{\text {nd }}$ Derivative & 0.1033 & 0.3009 & 0.4091 & 0.5550 \\
\hline $2^{\text {nd }}$ Derivative & 0.0284 & 0.0392 & 0.0284 & 0.0153 \\
\hline
\end{tabular}


The RMSEP values clearly show the good ability of the second derivative model to predict fructose levels in new samples with the decrease of the error associated. The model was the only one that had a good decrease of prediction error with the increase of latent variables. The best number of LVs for the prediction of the fructose content for new samples were four, where the mean of the predicted value is $0.0994 \mathrm{~g} / 100 \mathrm{~g}$ versus the average of the reference $0.0879 \mathrm{~g} / 100 \mathrm{~g}$. Figure 3 shows the prediction of fructose in external samples.

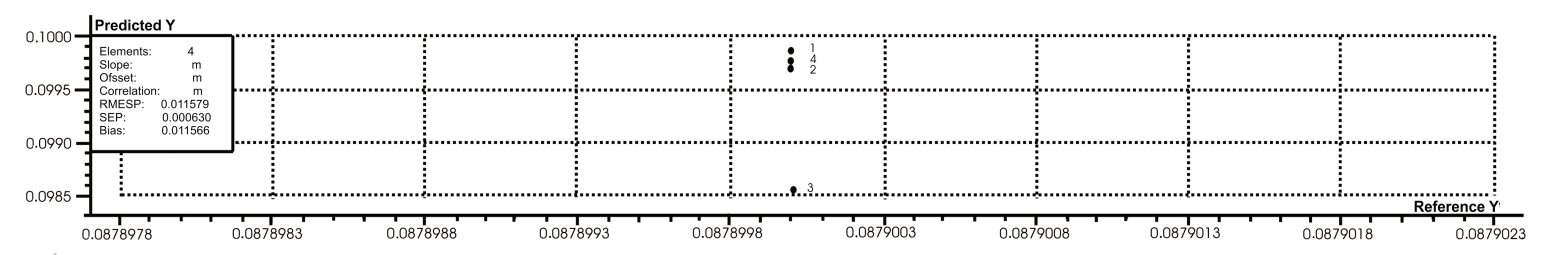

Figure 3. Prediction of fructose content.

Authors performed the coupling of Raman spectra obtained from prebiotic sugars with PLS analysis, obtaining weak correlations of the calibration and validation stages of the models, respectively, in the values of 0.989 and 0.984 [19]. Contrasting the best model obtained for fructose in which correlation assumed the value of 0.9941 .

In the determination of functional compounds in baby food, authors report the creation of prediction models using NIRS data. These models presented high values of prediction error even after performing spectral pre-treatments, the $1^{\text {st }}$ derivative, SNV and centering in the mean [23]. These results confirm the robustness of the model for prediction of fructose in relation to the most recent published works.

Table VI shows the calibration and validation parameters for each ideal model considered for sucrose prediction.

Table VI. Calibration and validation parameters for each sucrose model

\begin{tabular}{|c|c|c|c|c|}
\hline Model & RMSEC & Y-explained variance / \% & $r^{2}$ & RMSECV \\
\hline Crude data $^{a}$ & $0.0975\left(3^{b}\right)$ & $65.39(3)$ & $0.8086(3)$ & $0.1285(3)$ \\
\hline $\mathrm{MSC} / 1^{\text {st }}$ Derivative & $0.0297(7)$ & $96.16(7)$ & $0.9806(7)$ & $0.2469(2)$ \\
\hline MSC/Normalization & $0.0154(7)$ & $98.77(7)$ & $0.9938(7)$ & $0.2000(3)$ \\
\hline Normalization $/ 1^{\text {st }}$ Derivative & $0.0136(7)$ & $99.25(7)$ & $0.9962(7)$ & $0.2061(2)$ \\
\hline Normalization & $0.0077(7)$ & $99.66(7)$ & $0.9983(7)$ & $0.1638(4)$ \\
\hline
\end{tabular}

${ }^{a}$ Models submitted to Marten's uncertainty test; ${ }^{\mathrm{b}}$ Number of PCs

The elucidation of the predictive capacity of the models is shown in Table VII, considering only three latent variables.

Table VII. RMSEP values to predict sucrose contents in external samples

\begin{tabular}{|c|c|c|c|}
\hline Model & $1 \mathrm{LV}$ & $2 \mathrm{LV}$ & $3 \mathrm{LV}$ \\
\hline Crude data & 0.1984 & 0.1385 & 0.1399 \\
\hline $\mathrm{MSC} / 1^{\text {st }}$ Derivative & 1.8010 & 2.5878 & 1.8197 \\
\hline MSC/Normalization & 0.7026 & 1.9696 & 4.3923 \\
\hline Normalization $/ 1^{\text {st }}$ Derivative & 0.0683 & 0.2699 & 0.2121 \\
\hline Normalization & 0.1738 & 0.9347 & 0.2289 \\
\hline
\end{tabular}


These prediction error values have shown that the crude data model has the minimum RMSEP value for only two LVs, this error value being smaller than others. This model was the only one that had the decrease of prediction error with the increase of latent variables. The elimination of some wavenumbers improved the model, predicting a mean sucrose content in external samples of $0.4510 \mathrm{~g} / 100 \mathrm{~g}$, compared with the reference value $0.5150 \mathrm{~g} / 100 \mathrm{~g}$. Figure 4 shows the prediction in the external samples for this model.



Figure 4. Prediction of sucrose content.

Experiments involving chemical characterization of cassava with FT-MIR and construction of prediction models with PLS are not mentioned in the literature. Some authors use PLS together with infrared spectroscopy data to predict physicochemical properties. These authors had figures of merit and number of latent variables higher compared to models obtained using medium infrared spectroscopy and Raman spectroscopy $[24,25]$.

In spite of this, some authors report that FT-MIR spectroscopy is a technique with great advantage in showing a spectrum directly related to chemical information, as it was observed in the case of glucose, fructose and sucrose which have been quantified in many agricultural matrices by many methods among which infrared spectroscopy has been highlighted [26,13].

Some authors have used FT-MIR spectroscopy coupled to PLS regression to quantify many properties, generating models with RMSEP in the range of 4.3000-5.9000 g/100g to quantify phenolic compounds in red grape $[27,28]$.

The use of this coupling was reported involving Raman spectroscopy, showing a great possibility of applying the PLS regression with spectroscopy techniques [29]. In the determination of phenolic compounds in wine, some authors have found prediction error values ranging from 0.99 to $3.24 \mathrm{~g} / 100 \mathrm{~g}$. The use of the PLS1 algorithm is also reported as more advantageous in the creation of models for the prediction of sucrose, presenting RMSEP reduction of 13.6 to $10.0 \mathrm{~g} / \mathrm{L}$ in the prediction of the reference average content in direct determination of fructooligosaccharides treated by $\beta$-fructofuranosidases enzymes [30].

\section{CONCLUSIONS}

The pre-processing of spectral data was used to stabilize the constructed models. At this point, the second derivative was the best pre-processing for the prediction of glucose and fructose and the crude data explained better sucrose contents.

This work has shown that it is possible to do less use of classical analysis techniques in the repeatability of the determination of essential compounds in food matrices, from the creation of local models of multivariate regression by partial least squares. It is always important to expand the sampling to create ideal models of the studied properties, a factor that must be taken into account by future work.

Manuscript received Jan. 26, 2018; revised manuscript received April 23, 2018; accepted May 2, 2018. 


\section{REFERENCES}

1. Bayoumi, S. A. L.; Rowan, M. G.; Beeching, J. R.; Blagbrough, I. S. Phytochemistry, 2010, 71, pp 598-604.

2. http://www.embamoc.co.za/trade-industry/ [Accessed 23 January 2018].

3. Albuquerque, J. A. A.; Sediyama, T.; Silva, A. A.; Sediyama, C. S.; Alves, J. M. A.; Neto, F. A. Brazilian Journal of Agricultural Sciences, 2009, 4, pp 388-394.

4. Silva, R. N.; Quintino, F. P.; Monteiro, V. N.; Asquieri, E. R. Ciênc. Tecnol. Aliment., 2010, 30, pp 213-217.

5. Karoui, R.; Downey, G.; Blecker, C. Chemical Reviews, 2010, 110, pp 6144-6168.

6. Souza, A. M. de; Poppi, R. J. Química Nova, 2012, 1, pp 223-229.

7. Pierce, K. M.; Kehimkar, B.; Marney, L. C.; Hoggard, J. C.; Synovec, R. E. J. Chromatogr. A, 2012, 3, p 1255.

8. Gy, B.; Ovádi, Z.; Salgó, A. J. Near Infrared Spectrosc., 1998, 6, p 341.

9. Ferreira, M. M. C.; Antunes, A. M.; Melgo, M. S.; Volpe, P. L. O. Química Nova, 1999, 22, p 724.

10. Rebouças, M. V.; Barros Neto, B. J. Near Infrared Spectrosc., 2001, 9, p 263.

11. Sun, D. W. Infrared Spectroscopy for Food Quality Analysis and Control, Netherlands, 2009, chapter 1, p 275.

12. Scibisz, I.; Reich, M.; Bureau, S.; Gouble, B.; Causse, M.; Bertrand, D.; Renard, C. M. G. C. Food Chem., 2011, 125, p 1390.

13. Magwaza, L. S.; Opara, U. L.; Cronje, P. J. R.; Landahl, S.; Nieuwoudt, H. H.; Mouazen, A. M.; Nicolaï, B. M.; Terry, L. A. Scientia Horticurae, 2014, 165, p 421.

14. Sánchez, T.; Ceballos, H.; Dufour, D.; Ortiz, D.; Morante, N.; Calle, F.; Felde, T. Z.; Domínguez, M.; Davrieux, F. Food Chem., 2014, 151, p 444.

15. Alander, J. T.; Bochko, V.; Martinkauppi, B.; Saranwong, S.; Mantere, T. Int. J. Spectrosc., 2013, 36, p 2013.

16. Wei, M.; Geladi, P.; Lestander, T. A.; Xie, G.; Xiong, S. Anal Bioanal Chem, 2015, 407, p 5443.

17. Xu, L.; Chai, C. B.; She, Y. B.; Chen, L. J. J. Spectrosc., 2015, 8, p 2015.

18. Stitt, M.; Lilley R. M.; Gerhardt, R.; Heldt, H. W. Methods in Enzymol., 1986, 174, p 518.

19. Santos, M. I.; Andrade, C. A.; Tymczyszyn, E. E.; Zvaglia, A. G. Food Res. Int., 2014, 64, pp 514-519.

20. Wei, M.; Geladi, P.; Lestander, T. A.; Xie, G.; Xiong, S. Anal Bioanal Chem, 2015, 407, p 5443.

21. Xu, L.; Chai, C. B.; She, Y. B.; Chen, L. J. J. Spectroscopy, 2015, 8, p 2015.

22. Ayvaz, H.; Santos, A. M.; Moyseenko, J.; Kleinhenz, M.; Saona, L. E. R. Plant Foods Hum Nutr, 2015, 70, p 215.

23. Cascant, M. M.; Garrigues, S.; de la Guardia, M. Anal Bioanal Chem, 2015, 407, p 1961.

24. Henrique, C. M.; Teófilo, R. F.; Sabino, L.; Ferreira, M. M. C.; Cereda, M. P. J. Food Sci., 2007, 72, p E184.

25. Almeida, M. R.; Alves, R. S.; Nascimbem, L. B. L. R.; Stephani, R.; Poppi, R. J.; de Oliveira, L. F. C. Anal Bioanal Chem, 2010, 397, p 2693.

26. Ruiz-Altisent, M.; Ruiz-Garcia, L; Moreda, G.P.; Lu, R.; Hernandez-Sanchez, N.; Correa, E.C.; Diezma, B.; Nicolai, B.; García-Ramos, J. Computer and Electronics in Agriculture, 2010, 74, p 176.

27. Fragoso, S.; Aceña, L.; Guasch, J.; Mestres, M.; Busto, O. J. Agric. Food Chem., 2011, 59, p 10795.

28. Fragoso, S.; Aceña, L.; Guasch, J.; Busto, O.; Mestres, M. J. Agric. Food Chem., 2011, 59, p 2175.

29. Meza-Márquez, O. G.; Gallardo-Velázquez, T.; Dorantes-Álvarez, L.; Osorio-Revilla, G.; Arana, J. L. de La R. Analyst, 2011, 136, p 3355.

30. Trollope, K. M.; Volschenk, H.; Görgens, J. F.; Bro, R.; Nieuwoudt, H. H. Anal Bioanal Chem, 2015, 407, p 1661. 